\title{
Comparison of anal and rectal swabs in the diagnosis of anorectal gonorrhoea in women
}

\author{
BARBARA KOLATOR* AND PHILIP RODIN† \\ From the *Venereal Diseases Reference Laboratory and the †Whitechapel Clinic, The London Hospital, \\ London
}

SUMMARY Among 228 women with gonorrhoea (confirmed by culture), swabs taken blindly from the anal canal gave positive results in $26.3 \%$ and those taken from the rectum under direct vision in $27 \cdot 6 \%$. Swabs from both sites gave positive results in $23 \cdot 2 \%$ of patients, from the anal canal alone in $3 \cdot 1 \%$, and from the rectum alone in $4 \cdot 4 \%$. Thus, culture of anal canal swabs seems to give as reliable results as rectal swabs when proctoscopy cannot be carried out.

\section{Introduction}

Rectal swabs for microscopical examination and culture are taken routinely from women in only a few clinics in England and Wales. Even in the investigation of contacts of gonorrhoea rectal swabs are taken in only $20 \%$ of clinics (Adler, 1978). The rectum is commonly affected in women with gonorrhoea, and it may be the only site from which the organism is recovered in about $5 \%$ of cases. The subject was reviewed briefly by Bhattacharyya and Jephcott (1974).

Thus microscopy and culture of rectal swabs are important in detecting some cases of gonorrhoea. Furthermore, although the diagnosis can usually be made by isolating the organism from other sites, it is necessary to prove that any associated rectal infection has also responded to treatment (Schroeter and Reynolds, 1972).

Although examination by proctoscopy is preferred, because it allows a clinical assessment to be made and material for culture to be selected under direct vision, not all patients agree to this examination. Reports on the success of taking anal swabs for the isolation of gonococci have varied. Bhattacharyya and Jephcott (1974), in a small series of female patients, found that anal swabs gave fewer positive results than rectal swabs in the detection of gonorrhoea. Deheragoda (1977), however, obtained almost as good results with anal swabs as with rectal swabs in male homosexuals. In the present study we

Address for reprints: Dr P. Rodin, Whitechapel Clinic, The London Hospital, London E1 IBB

Received for publication 6 October 1978 compare the results from anal and rectal specimens in a larger series of female patients.

\section{Material and methods}

As well as routine examination of cervical and urethral specimens, rectal specimens for Gram staining and culture were taken via a proctoscope from all new female patients attending the Whitechapel Clinic of the London Hospital. For the present study anal swabs were also taken. The swab was introduced blindly 2 or $3 \mathrm{~cm}$ into the anal canal and inoculated on to one half of a culture plate (brain heart infusion blood agar with $3 \mu \mathrm{g} / \mathrm{ml}$ vancomycin and $7.5 \mu \mathrm{g} / \mathrm{ml}$ colistin); the other half of the plate was reserved for inoculation of the rectal swab taken next under direct vision through a proctoscope. Organisms were identified as gonococci on the basis of their colonial appearance and microscopical morphology in Gram-stained smears, of positive results to the oxidase test, and of acid production from glucose but not maltose, lactose, or sucrose.

\section{Results}

During the course of the study gonorrhoea was confirmed by culture at one examination in 228 women (Table 1). The frequency of isolation from each site is shown in Table 1 and a comparison of the results from anal canal and rectal specimens is given in Table 2. The results of the Gram-stained smears for 228 women with culture-positive gonorrhoea are given in Table 3. Smears from anal canal specimens were not made. 
Table 1 Site of positive isolation in 228 women with culture-positive gonorrhoea

\begin{tabular}{|c|c|c|c|c|c|c|c|c|}
\hline \multirow{3}{*}{ No. of patients } & \multicolumn{8}{|c|}{ No. of swabs giving positive results at each site } \\
\hline & \multicolumn{2}{|c|}{ Urethra } & \multicolumn{2}{|c|}{ Cervix } & \multicolumn{2}{|c|}{ Anal canal } & \multicolumn{2}{|c|}{ Rectum } \\
\hline & No. & $\%$ & No. & $\%$ & No. & $\%$ & No. & $\%$ \\
\hline 228 & 203 & 89 & 218 & $95 \cdot 6$ & 60 & $26 \cdot 3$ & 63 & 27 \\
\hline
\end{tabular}

Table 2 Comparison of results from anal canal and rectal specimens in 228 women with culture-positive gonorrhoea

\begin{tabular}{|c|c|c|c|c|c|c|c|}
\hline \multicolumn{2}{|c|}{$\begin{array}{l}\text { Anal canal or } \\
\text { rectum or both }\end{array}$} & \multicolumn{2}{|c|}{$\begin{array}{l}\text { Anal canal } \\
\text { and rectum }\end{array}$} & \multicolumn{2}{|c|}{$\begin{array}{l}\text { Anal canal } \\
\text { alone }\end{array}$} & \multicolumn{2}{|c|}{$\begin{array}{l}\text { Rectulum } \\
\text { alone }\end{array}$} \\
\hline No. & $\sigma_{0}$ & No. & $\%$ & No. & $\%$ & No. & $\%$ \\
\hline $70^{*}$ & $30 \cdot 7$ & 53 & $23 \cdot 2$ & 7 & $3 \cdot 1$ & 10 & $4 \cdot 4$ \\
\hline
\end{tabular}

*In five $(2 \cdot 2 \%)$ the cervical and urethral cultures gave negative results

Table 3 Results of Gram-stained smears for 228 women with culture-positive gonorrhoea

\begin{tabular}{|c|c|c|c|c|c|c|c|}
\hline \multicolumn{6}{|c|}{$\begin{array}{l}\text { Site of specimens giving positive results by } \\
\text { Gram-staining }\end{array}$} & \multicolumn{2}{|c|}{$\begin{array}{l}\text { Total positive } \\
\text { at one or more } \\
\text { sites }\end{array}$} \\
\hline No. & $\%$ & No. & $\%$ & No. & $\%$ & No. & $\%$ \\
\hline 97 & $42 \cdot 5$ & 157 & $68 \cdot 9$ & 15 & $6 \cdot 6$ & 179 & $78 \cdot 5$ \\
\hline
\end{tabular}

\section{Discussion}

The results show that cultures of anal canal specimens taken blindly give comparable results to those taken under direct vision through a proctoscope. Bhattacharyya and Jephcott (1974) found that culture of anal canal swabs in women gave less reliable results, but this might have been due to loss of a small inoculum in Stuart's transport medium. Deheragoda (1977), using direct plating for male homosexuals, obtained similar results to ours.

We still take specimens for the diagnosis of gonorrhoea through a proctoscope and direct vision is essential when looking for evidence of non-specific proctitis. There are a few patients, however, who object to proctoscopy, and it would certainly be worth taking an anal swab in these cases.

Barlow and Phillips (1978) found that Gramstained urethral smears contributed little to the diagnosis of gonorrhoea in women and suggested that they could be omitted from routine examination. These workers found that only $12 \cdot 3 \%$ of urethral smears gave positive results; the results of the urethral smear enabled the diagnosis to be made at the first visit so that treatment could be started-on the basis of a positive result by urethral smear alone-in only $2 \cdot 6 \%$ of cases. These results seem at variance with those of most other workers. In our study, urethral smears gave positive results in $42.5 \%$ of cases, and we were able to start treatment, when it was the only test giving positive results at the first visit, in $6.6 \%$ of our cases; however, the corresponding figure was only $0.9 \%$ with rectal smears.

We thank $\operatorname{Dr}$ A. E. Wilkinson, Director of the Venereal Disease Reference Laboratory, for his advice.

\section{References}

Adler, M. W. (1978). Diagnostic, treatment, and reporting criteria for gonorrhoea in sexually transmitted disease clinics in England and Wales: 1. Diagnosis. British Journal of Venereal Diseases, 54. 10-14.

Barlow, D. and Phillips, I. (1978). Gonorrhoea in women. Diagnostic, clinical, and laboratory aspects. Lancet, 1, 761-764.

Bhattacharyya, M. N., and Jephcott, A. E. (1974). Diagnosis of gonorrhoca in women. Role of the rectal sample. British Journal of Venereal Diseases, 50, 109-112.

Deheragoda. P. (1977). Diagnosis of rectal gonorrhoea by blind anorectal swabs compared with direct vision swabs taken via a proctoscope. British Journal of Venereal Diseases, 53, 311-313.

Schroeter, A. L., and Reynolds, G. (1972). The rectal culture as a test of cure of gonorrhoea in the female. Journal of Infectious Diseases, 125, 499-503. 